Article

\title{
Does More Mean Better? Exploring the Relationship between Report Completeness and Environmental Sustainability
}

\author{
Armando Calabrese ${ }^{1,+}$, Roberta Costa ${ }^{1, *,+} \mathbb{D}$, Nathan Levialdi ${ }^{1,+}$, Tamara Menichini ${ }^{2,+}$ \\ and Roberth Andres Villazon Montalvan ${ }^{1,+}$ \\ 1 Department of Enterprise Engineering, University of Rome “Tor Vergata”, 00133 Rome, Italy; \\ calabrese@dii.uniroma2.it (A.C.); levialdi@dii.uniroma2.it (N.L.); \\ roberthandres.villazonmontalvan@students.uniroma2.eu (R.A.V.M.) \\ 2 Department of Industrial and Mechanical Engineering, University of Rome "Niccolò Cusano", \\ 00166 Rome, Italy; tamara.menichini@unicusano.it \\ * Correspondence: roberta.costa@uniroma2.it; Tel.: +39-06-72597799; Fax: +39-06-72597951 \\ $\dagger$ These authors contributed equally to this work.
}

Received: 18 November 2020; Accepted: 17 December 2020; Published: 19 December 2020

\begin{abstract}
The reliability of sustainability reporting can impact sustainable development and should provide relevant information to financial analysts, investors, and other stakeholders by reducing information asymmetry between them and management. Nevertheless, its utility is often undermined by a lack of the disclosure information's trustability. This paper aims to evaluate if the completeness of the sustainability report's environmental quantitative information is a reliable indicator of the company's real commitment to environmental sustainability. The paper analyzes the relationship between the report's completeness and the environmental performance evaluated by data of an independent third party. Fifty Italian companies that have submitted complete data on $\mathrm{CO}_{2}$ emissions to the European Union Emissions Trade Scheme (EU ETS) in the six years from 2008-2013 and published sustainability reports have been evaluated. Results indicate that reporting completeness is not correlated with better environmental performance, and consequently with greater commitment to environmental sustainability, thus suggesting the potential existence of credibility gaps.
\end{abstract}

Keywords: $\mathrm{CO}_{2}$ emissions; sustainability report; environmental performance; CSR; credibility gap; report completeness

\section{Introduction}

Companies facilitate sustainable development through sustainability strategies that improve process efficiency, attract customers and new business, and improve their image. Thus, they achieve and maintain a competitive advantage [1-3]. In this context, sustainability accounting is a specific tool that companies can utilize when dealing with uncertainties and risks regarding environmental issues, guiding their managerial decisions on the triple bottom line of social, environmental, and financial sustainability [4]. A sustainability report is also the means of communicating sustainability accounting that can attract analysts and investors because of the possible reduction of information asymmetry $[5,6]$.

Through their sustainability report, companies disclose information on their activities that impacts the economic, social, and environmental spheres [7]. However, as Bernard et al. [8] point out, because sustainability reporting involves voluntary disclosure, the report may be more indicative of the company's willingness to reveal indicators and information, rather than fully informing about its real sustainability. Moreover, as these same authors suggest, the content of the company's report will ultimately only be legitimized by stakeholder acceptance that the disclosed information is 
trustworthy. Thus, in the past decade, there have been questions about the quality and credibility of reporting practices; and various authors have focused on trustability and reliability of the information provided [9-12]. Subsequently, some organizations involved in financial scandals have produced brilliant sustainability reports, using them as facades for their sustainability conduct and as disguises of their real poor performance [13].

Furthermore, sustainability reporting has been criticized for its lack of relevance [14] and for its ineffectiveness in supporting sustainable development [15]. To overcome these problems, various initiatives have been developed, such as the GRI (Global Reporting Initiative) standard, with the aim of standardizing sustainability reports, making them more understandable and reliable. However, researchers have found that sustainability reporting continues to provide heterogeneous information, evaluated on the basis of different standards and indicators; and that this is a persisting widespread problem $[8,16]$. At present, there is no consensus about choosing the measures to utilize as proxy for the quality of information reported by companies. In about $80 \%$ of environmental reporting research, "quality" is assessed in only one or two dimensions [17]. Furthermore, some scholars and organizations have developed score systems to measure reporting quality [18]. Nevertheless, recent studies have evidenced that the quality of disclosure is characterized by various dimensions, such as quantity, breadth, depth, and time; and that report quality should be assessed by multidimensional models [19].

Investigating the reporting practice quality is favored by the growing interest in the potential advantages of the sustainability reports' completeness and credibility for investors and for financial stakeholders $[5,20]$. Regarding this, literature contains a limited number of contributions analyzing the relationship between the completeness of a sustainability report and the company's real sustainability performance (e.g., $[10,20,21])$. Through these analyses, the authors have investigated the extent to which companies are accountable to their stakeholders through their reporting, stressing the importance of verified data to ensure credibility. Nevertheless, a potential criticism is that even though these authors have analyzed the quality of sustainability reporting, they have failed to use verified data to assess the companies' real commitment to sustainability.

Therefore, this paper aims to understand if the completeness, which is a dimension of the quality, of a sustainability report guarantees that an organization is really committed to environmental sustainability. In particular, the proposed methodological approach is based on the analysis of the relationship between certified environmental performance and report completeness to demonstrate whether the latter is a reliable indicator of the company's commitment to environmental sustainability. The completeness of quantitative data is defined as the number of quantitative environmental indicators reported. The originality of this paper to environmental reporting research is to utilize data certified by a neutral third party (i.e., the registry of the European Union Emissions Trade Scheme (EU ETS)) to assess environmental performance, as a proxy of the companies' real commitment regarding environmental sustainability. Using this approach, the authors aim to evaluate the extent to which companies are accountable to their stakeholders through their reporting, stressing the importance of verified data to ensure credibility analysis.

\section{Background Literature}

\subsection{Sustainability Reporting and Credibility Gap}

Suchman [22] (p. 574) defines legitimacy as "a generalized perception or assumption that the actions of an entity are desirable, proper, or appropriate within some socially constructed system of norms, values, beliefs, and definitions." To remain competitive, a company must operate within the limits of what society identifies as socially acceptable behaviour $[23,24]$ and act to remain legitimate in the eyes of its stakeholders [25-27]. Exploiting sustainability practices and sharing them with stakeholders are key factors in the company's emergence and advancement in the current competitive context [8]. In addition, the company's sustainability reporting practices are greatly influential in establishing its legitimacy [20]. 
Sustainability reporting should illustrate the company's policies, performance, and commitment toward sustainability [28]. According to Schneider, [29] sustainability reporting is derived from both sustainability accounting and sustainability management. Bernard et al. [8] argue that effective reporting should in itself improve the company's sustainability and environmental performance. Furthermore, reporting practices should increase the stakeholders' knowledge about corporate sustainability activities and results, although this does not always happen [20]. Following previous literature, Skouloudis et al. [30] and Bernard et al. [8] highlight four main reasons why a company conducts sustainability reporting: (1) to reduce operating costs; (2) to improve stakeholder relations; (3) to promote a company image; and (4) to gain competitive advantage.

As described by Lopes and Rodrigues [31], stakeholders tend to perceive legitimacy on the basis of their expectations and perceptions, rather than on the actual information disclosed. According to the "legitimacy theory" [7,8,32], the tactic for achieving corporate legitimacy can be founded on the use of unsupported "green" words and actions [33]. Michelon et al. [20] and Romero et al. [7] argue that under the legitimacy theory, two lines of practice can take place in sustainability communication: (1) the substantive approach, in which there is a functional commitment to sustainability and the quality of disclosure tends to be higher; and (2) the symbolic approach, in which efforts are directed more at developing positive perceptions among stakeholders, not necessarily with actions creating a favorable image. The substantive approach to sustainability reporting should correspond to communication processes that have a higher quality and quantity of information [7]. Instead, the symbolic approach to sustainability reporting could induce differences between what is published and what is actually performed by the reporting company [34]. Thus, this undermines the legitimacy of the disclosed information and creates a "credibility gap" [20]. Lock and Seele [35] and Mazzotta et al. [36] emphasize the need for a multidimensional index to assess credibility. Nevertheless, the methodological approach proposed in this paper is based on identifying the presence of the potential "credibility gaps" without measuring credibility. Therefore, credibility is intended as the reliability of the information disclosed in the sustainability report, and credibility gap as stakeholders' concerns about the capacity or intention of reporting companies about this issue [37].

Impression management theory argues that companies exploit information asymmetry between companies and stakeholders by manipulating information disclosed in sustainability reports through strategies of information improvement or obfuscation [12,38-40]. Obfuscation strategy is a narrative writing technique that obscures contents and confuses readers (e.g., [41]); on the contrary, the improvement strategy emphasizes positive organizational results (e.g., [39]). Various authors have observed that even when some companies voluntarily provide truthful information disclosure [42], their publications use a narrative style and contain qualitative information [43-45].

The difficulty in interpreting disclosed narrative, qualitative information permits companies to utilize greenwashing practices [46] and describes a "greenwashing scenario" in which the company not only takes a symbolic reporting approach, but also conveys misleading reporting of positive sustainability actions. Moreover, greenwashing often makes it difficult for readers to identify and to interpret the main sustainability indicators [32], publishing meaningless information, instead of providing relevant details [47].

Consequently, some authors remain skeptical about sustainability reports [15,21,48-50]. Schönherr et al. [50] state that in the most favorable cases, sustainability reporting focuses on what the companies do, rather than on what they achieve in sustainable development. Thus, Michelon et al. [20] have summed up that "research on sustainability disclosure points to an increasing lack of completeness and decreasing amount of credibility in the information reported."

Focusing on this credibility problem, various authors have mentioned the importance of disseminating measurable and quantitative information in sustainability reports to limit or to exclude the credibility gap (e.g., [7,10,51,52]). Moreover, report completeness, that has been evaluated by the number of disclosed items, seems to be a key indicator of its reliability (e.g., $[10,20,43])$. 
Some authors $[21,46,53]$, in studying the prevalence of greenwashing and the symbolic approach, have concluded that these will be more common in companies' environmental reporting, rather than in social or economic. Moreover, because stakeholders have become more aware of the effects of greenhouse gas emissions, global warming, and climate change, as well as the 2030 United Nations Agenda for Sustainable Development, the authentication of reporting on environmental sustainability will become increasingly essential for companies to attain credibility. According to O'Donovan [23], effective environmental reporting is fundamental for any company to achieve sustainable development and to demonstrate responsible conduct.

Thus, this paper investigates the credibility of sustainability reports by verifying the relationship between report completeness and commitment to environmental sustainability. In addition, the originality of this study lies in utilizing environmental performances certified by an independent third party (i.e., EU ETS), as a proxy for the companies' real commitment to sustainability.

\subsection{Environmental Sustainability and Verified Emissions}

Environmental questions have been on the international agenda since the 1972 United Nations (UN) Stockholm Conference. In 1987, the World Commission on Environment Development defined "sustainability" in the report "Our Common Future", giving the term further attention. Now, there is more global awareness in adopting a sustainable approach, weighing with equal importance the social, economic, and environmental impact for both current and future generations [54-57]. The sphere of sustainable environmental planning and management is broad and encompasses both nature and society. It is multifaceted and has been studied from different perspectives [58].

"Environmental impact" is any positive or negative change in the quality of an environment. In general, positive environmental performance is achieved through activities comprising minimal negative environmental impacts [59]. Moreover, the measurement of environmental performance requires two perspectives: pre-impact and post-impact assessment. Pre-impact assessment considers the environmental impacts before any activity with the potential of significant degradation, and post-impact assessment measures the environmental status at some later date [59]. Such assessments involve measurement of key indicators, whose values are then compared to accepted standards, and can be used to judge whether the impacts of corporate activities are acceptable or not [58]. Subsequently, literature proposes sustainability indicators for monitoring, evaluating, and comparing environmental performances within different industries [60-62].

Therefore, pre-/post-impact assessments are instruments of environmental policy by international organizations (World Bank, International Monetary Fund (IMF), UN, etc.), by individual jurisdictions (countries, regions, departments, and municipalities), and also by the private sector. In 1994, the UN Framework Convention on Climate Change recognised the legitimacy of pre-/post-impact assessment of initiatives to alleviate or to adapt to climate change. Then, the 1997 Kyoto Protocol set measurable limits on greenhouse gas emissions, aiming at an overall reduction of $5.2 \%$ by 2012 [63]. This protocol established a country's reduction based upon its national income and industrialization. High-income, advanced countries have been subject to mandatory quantified objectives; while middle-income, low-income, and the least-developed countries have been expected to toughen national policies and governance to implement the protocol objectives.

In 2003, the European Parliament and the Council of the European Union adopted EC Directive 2003/87 establishing a scheme for trading in greenhouse gas emissions allowances. The main objective has been to reduce emissions in a cost-effective and economically efficient manner [64]. In particular, the Directive established a European Union Emissions Trading Scheme (EU ETS), inspired by the Kyoto Protocol, as the fundamental tool for governance of emission reduction. The EU ETS regulates the sources of almost $50 \%$ of total $\mathrm{CO}_{2}$ emissions within the European Union and $40 \%$ of total greenhouse gas (GHG) emissions. Di Pillo et al. [65] stress that the ETS is the first and the most important GHG emissions' allowance trading program in the world. It is generally deemed the basis of the European climate policy and has inspired several other countries to adopt similar instruments around the 
world [66]. The dynamics of the ETS are based on the "cap and trade" mechanism. A company emitting less than its upper limit can offer the difference (gap) on the market to trade with any company that has exceeded its upper limit, neutralizing $\mathrm{CO}_{2}$ emissions. The ETS' primary goal is target reduction, but it also provides incentives for technological innovation [67].

According to Di Pillo et al. [65], European GHG emissions have declined by 18\% from 1990 to 2012. Moreover, in 2009, the European Council adopted the 20-20-20 Climate and Energy Package. It set the 2020 objectives as improved energy efficiency and reduction of GHG emissions by $20 \%$ each, as well as achieving a 20\% share for renewable sources in energy utilization. In 2016, the goals for 2020-2030 were set even higher with a $40 \%$ reduction of GHG emissions and a $27 \%$ increase in renewable energy. Under EU regulations, companies must disclose information on their $\mathrm{CO}_{2}$ emissions as a measure of sustainability and environmental performance $[68,69]$. In fact, for both GRI and non-GRI reporting companies, the most widely reported environmental indicator is $\mathrm{CO}_{2}$ emissions [8].

\section{Research Design}

In this paper, the methodological approach investigates the relationship between the completeness of the sustainability report and the company's real commitment to environmental sustainability. Following previous studies, this proposed approach utilizes the completeness of quantitative information as a dimension of the quality report. The originality of this paper is to adopt third-party certified environmental performances of $\mathrm{CO}_{2}$ emissions' reduction, as a proxy for the companies' real commitment to environmental sustainability. Although the need to use certified data has limited the study to one environmental sustainability indicator, $\mathrm{CO}_{2}$ emissions reduction has been noted in literature as a proxy for environmental sustainability in a climate change emergency $[8,68-70]$. Moreover, a reduction in $\mathrm{CO}_{2}$ emissions could indicate a shift in technological innovation, a better utilization of the energy supply, a change toward renewable energy, less transportation through the supply chain, and efficient production. In particular, environmental performance is determined by the companies' $\mathrm{CO}_{2}$ emissions per year as reported in the Union Registry for EU ETS. The EU ETS has been designed to implement the EU climate policy, and it has been in operation for 13 years. It applies to all $28 \mathrm{EU}$ member countries plus Iceland, Norway, and Liechtenstein. Given such legislative force and scope, the Union Registry provides reliable information, useful for the adoption of $\mathrm{CO}_{2}$ emissions as a measure of the companies' general environmental performance throughout Europe.

\subsection{Sample}

This paper utilizes data certified by a reliable independent third party (EU ETS) as a proxy for the companies' commitment to environmental sustainability and differs from previous studies. While carrying out this exploratory study, the authors had access to the Italian EU ETS database of $\mathrm{CO}_{2}$ emissions from 2008-2013. Italian companies are an interesting sample because from 2008-2013, Italy ranked third for $\mathrm{CO}_{2}$ emissions in the European Union [71] and fourth in GDP.

The group studied is comprised of 237 Italian companies that submitted complete data on $\mathrm{CO}_{2}$ emissions to the Union Registry in the six years from 2008-2013. The study analyzes the 2013 report completeness. When the firm's reporting is more experienced, its sustainability report is more accurate [35,72]. Therefore, the companies that have not published a sustainability report have been eliminated from the initial 237 sample. The eliminated companies have not published a sustainability report even in the previous years. The final sample of 50 companies belong to 21 economic sectors of the NACE (Statistical Classification of Economic Activities in the European Community). Only 8\% of the companies are in environmentally non-sensitive sectors (service industry); $82 \%$ belong to environmentally sensitive sectors (energy, manufacturing, water treatment, etc.); $10 \%$ are large companies; and $90 \%$ are medium-large.

The absolute values of total $\mathrm{CO}_{2}$ emissions would not be relevant in comparing environmental performances, given that the companies are of different sizes and belong to diverse industries characterized by different outputs [65]. To overcome this problem, as recommended by the G4 GRI 
Guidelines [8], the analysis was based on the comparison of "carbon emission intensity," which is obtained by normalizing a company's yearly $\mathrm{CO}_{2}$ emissions through its annual turnover $[65,73]$.

The total annual emissions for each company in the time series 2008-2013 were normalized and standardized according to:

$$
\hat{C O}_{2 i, t}=z_{i, t}=\frac{\mathrm{CO}_{2_{i, t}}-\mu_{i}}{\sigma_{i}} t \in(2008, \ldots, 2013)
$$

where respectively $\mathrm{CO}_{2, t}$ is the $t$-th value of the aforementioned normalized time series; $\mu_{i}$ is the average value; and $\sigma_{i}$ is the standard deviation of the $i$-th company.

\subsection{Variables}

The companies' environmental performance was assessed through four variables $\left(E_{1}, E_{2}, E_{3}\right.$, and $E_{4}$ ), which encompass various perspectives regarding sustainability behaviors in the area of $\mathrm{CO}_{2}$ emissions. The analyses of $E_{1}, E_{2}$, and $E_{4}$ were performed using the normalized values of $\mathrm{CO}_{2}$ emission intensity $\left(\mathrm{CO}_{2, t}\right)$, while $E_{3}$ used the normalized and standardized values $\left(\hat{C O}_{2 i, t}\right)$.

(1) $E_{1}$ is the "total percentage variation in $\mathrm{CO}_{2}$ emissions intensity" during 2008-2013 determined as:

$$
E_{1, i}=\frac{\mathrm{CO}_{2_{i, 2013}}-\mathrm{CO}_{2_{i, 2008}}}{\mathrm{CO}_{2_{i, 2008}}}
$$

where $\mathrm{CO}_{2, t}$ corresponds to the normalized $\mathrm{CO}_{2}$ emissions in $\mathrm{kg} / €$ of company " $i$ " in the year " $t$ ".

(2) $E_{2}$ is the "average annual percentage variation in $\mathrm{CO}_{2}$ emissions intensity" calculated during 2008-2013 and defined as:

$$
E_{2, i}=\frac{\sum_{t=2008}^{2012} \frac{\mathrm{CO}_{2_{i, t+1}}-\mathrm{CO}_{2_{i, t}}}{\mathrm{CO}_{2, t}}}{5}
$$

where $\mathrm{CO}_{2, t}$ corresponds to the normalized $\mathrm{CO}_{2}$ emissions in $\mathrm{kg} / €$ of company " $i$ " in the year " $t$ ".

(3) $E_{3}$ is the "standardized slope of the regression line of $\mathrm{CO}_{2}$ emissions intensity" during 2008-2013, calculated for each company, using the normalized and standardized values of $\mathrm{CO}_{2}$ emission intensity $\left(\hat{\mathrm{C}} \mathrm{O}_{2 i, t}\right)$.

(4) $E_{4}$ is the "index of commitment to $\mathrm{CO}_{2}$ emissions reduction" calculated as:

$$
E_{4, i}=\frac{\sum_{t=2008}^{2012}\left\{\begin{array}{l}
1 \text { if } \mathrm{CO}_{2_{i, t+1}}-\mathrm{CO}_{2_{i, t}}<0 \\
0 \text { if } \mathrm{CO}_{2_{i, t+1}}-\mathrm{CO}_{2_{i, t}} \geq 0
\end{array}\right.}{5}
$$

From 2008 until 2013, the periods were divided into five subperiods: 2008-2009; 2009-2010; 2010-2011; 2011-2012; 2012-2013. It is the $E_{4, i}$ index that indicated the steadiness of the company in reducing $\mathrm{CO}_{2}$ emissions across these subperiods. The index ranged from 0 to 1 , with 1 corresponding to a highly committed company that continuously reduced $\mathrm{CO}_{2}$ emissions; and 0 to a company that never reduced $\mathrm{CO}_{2}$ emissions during the 2008-2013 subperiods. The higher the value of $E_{4, i}$, the higher the commitment of the i-th company to $\mathrm{CO}_{2}$ emissions reduction.

The proposed methodological approach compared the completeness of the companies' sustainability reports to their real commitment to environmental sustainability. Following previous studies, completeness (e.g., $[10,20]$ ) and the presence of quantitative information (e.g., $[7,51])$ are both related to the quality of the sustainability report. Thus, the sustainability report was analyzed through the "completeness of quantitative information," cited as completeness for simplicity, that was calculated by the number of measurable environmental indicators disclosed. Finally, the analysis focused on measuring the company's "reporting experience" according to the accumulated years of sustainability reporting to verify if this variable influences the completeness of the company's report and its commitment to environmental sustainability in $\mathrm{CO}_{2}$ emissions reduction. 


\section{Results}

The $E_{1}$ variable describes the companies' environmental performance during 2008-2013 in general terms, subsequently it only compares emissions intensity between the first and final years of the period. The $E_{1}$ analysis indicated that about two-thirds of sampled companies achieved reduction in emissions intensity during 2008-2013.

However, the $E_{1}$ indicator is incapable of revealing the subperiod environmental performances (2008-2009, 2009-2010, etc.). For example, a company could experience emission growth over some of the subperiods while still achieving a reduction over the period as a whole, or vice versa. Using the $E_{2}$ variable, the proposed approach also explored the subperiod performances.

This analysis showed that $50 \%$ of companies achieved reductions in both the $E_{1}$ and $E_{2}$ variables, while $40 \%$ of companies experienced growth in both variables. Finally, $10 \%$ of companies simultaneously presented a negative value of $E_{1}$ and a positive value of $E_{2}$.

The $E_{3}$ variable describes the environmental performance of the individual companies through the standardized slope of the regression line of emissions intensity. This variable estimates the trend in the companies' behaviour; and thus it is an indicative, orienting variable of what to expect in environmental performance. The analysis showed that $50 \%$ of the companies with constant emissions reduction ( $E_{1}$ and $E_{2}$ both negative) showed a slope lower than $-0.25\left(E_{3} \leq-0.25\right)$, while the other $50 \%$ displayed slope values from -0.34 to $0.56\left(-0.34 \leq E_{3} \leq 0.56\right)$.

Regarding $E_{4}$, the index of commitment to emissions reduction in $8 \%$ of the sampled companies demonstrates a strong commitment $\left(E_{4}=1\right)$, showing a constant reduction in emissions during the six-year period under study; and 52\% demonstrated a medium commitment $\left(0.6 \leq E_{4}<1\right)$. The remaining $40 \%$ of companies demonstrated a scarce commitment $\left(E_{4} \leq 0.4\right)$. The overall outcomes indicated that $42 \%$ of the sample demonstrated a substantial effort in emissions reduction and environmental sustainability $\left(E_{1}<0 ; E_{2}<0 ; E_{3}<-0.25\right.$ and $\left.E_{4} \geq 0.6\right)$.

The number of measurable environmental indicators that have been disclosed by the company served as the proxy of report completeness. On average, the sampled companies reported a range of 1 to 15 quantitative items, with an average of about 7 quantitative items per company (Table 1). Specifically, the sustainability reports under analysis contain quantitative indicators describing environmental performance through the emissions produced by the company. They show the environmental performance of the companies: $\mathrm{CO}_{2}$ emissions, $\mathrm{NO}_{\mathrm{x}}$ emissions, $\mathrm{CH}_{4}$ emissions, total GHG emissions, $\mathrm{SO}_{2}$ emissions, $\mathrm{COV}$ emissions, dioxin emissions, particulate matter, and emissions of heavy metal matters. Furthermore, other quantitative environmental indicators were disclosed: investments for improving environmental performance, waste, fuel consumption, fossil fuels, steam, water withdrawal, biodiversity, water consumption, recycled water, water discharge, spills, electricity consumption, raw materials, energy efficiency, asbestos abatement, and additives. Moreover, regarding reporting experience, the companies under examination filed sustainability reports from one to nineteen years, with the average being 6.22 years. Furthermore, $80 \%$ of the sample reported that their sustainability practices follow the GRI standard guidelines.

Table 1. Descriptive statistics of the variables.

\begin{tabular}{lcccccc}
\hline & Reporting Experience & Completeness & $\boldsymbol{E}_{\mathbf{1}}$ & $\boldsymbol{E}_{\mathbf{2}}$ & $\boldsymbol{E}_{\mathbf{3}}$ & $\boldsymbol{E}_{\mathbf{4}}$ \\
\hline Mean & 6.22 & 6.86 & 0.1086 & 0.0272 & -0.1280 & 0.5760 \\
Median & 6.00 & 6.00 & -0.1565 & -0.0032 & -0.3069 & 0.6000 \\
Std. & 3.86 & 2.86 & 0.8996 & 0.1608 & 0.3857 & 0.2378 \\
Deviation & 1.00 & 1.00 & -0.9812 & -0.3176 & -0.5693 & 0.2000 \\
Minimum & 19.00 & 15.00 & 3.8803 & 0.4865 & 0.5621 & 1.0000 \\
Maximum & & & & & & \\
\hline
\end{tabular}

This analysis illustrated a weak positive, but significant correlation (Table 2) between completeness (i.e., the number of quantitative environmental indicators), and respectively the "total percentage 
variation in $\mathrm{CO}_{2}$ emissions intensity" $E_{1}(\mathrm{r}=0.24 ; p=0.04)$; the "average annual percentage variation in $\mathrm{CO}_{2}$ emissions intensity" $E_{2}(\mathrm{r}=0.24, p=0.02)$; and the "standardized slope of the regression line of $\mathrm{CO}_{2}$ emissions intensity" $E_{3}(\mathrm{r}=0.25 p=0.04)$. These correlations indicate that those companies disclosing a greater number of environmental quantitative indicators actually achieved a less satisfactory environmental performance in variations of emissions intensity.

Table 2. Correlation matrix.

\begin{tabular}{lcccccc}
\hline & Reporting Experience & Completeness & $E_{1}$ & $E_{2}$ & $E_{3}$ & $E_{4}$ \\
\hline Reporting & 1 & & & & & \\
Experience & -0.140 & 1 & & & & \\
Completeness & -0.030 & $0.243^{*}$ & 1 & & & \\
$E_{1}$ & -0.035 & $0.242^{*}$ & $0.886^{* *}$ & 1 & & \\
$E_{2}$ & -0.047 & $0.246^{*}$ & $0.769^{* *}$ & $0.765^{* *}$ & 1 & \\
$E_{3}$ & 0.090 & -0.143 & $-0.662^{* *}$ & $-0.647^{* *}$ & $-0.730^{* *}$ & 1 \\
$E_{4}$ & & & & & & \\
\hline
\end{tabular}

Notes: Number of observations $n=50 ;{ }^{*}$ correlation is significant at the 0.05 level; ${ }^{* *}$ correlation is significant at the 0.01 level.

Furthermore, there was no significant statistical correlation between reporting experience and the environmental performance variables, nor between reporting experience and report completeness. The sector (environmentally sensitive versus non-sensitive) and the size of the companies had no statistically significant correlations with $E_{1}, E_{2}, E_{3}$ and $E_{4}$.

For a broader analysis, contingency tables were prepared, relating the environmental performance with the report completeness, thereby obtaining discrete representations of the joint probability distribution between the two variables. For this purpose, the range of values of the level of completeness, quantified by the number of quantitative environmental indicators, was subdivided into three categories using the percentile approach, often referred to as "binning." Using this, the category titled "low" corresponds to the lowest quartile of the 50 companies in terms of their percentile ranking for report completeness; the "medium" category corresponds to the two middle quartiles; and the "high" category comprises the companies in the highest quartile [74]. In addition, the companies of the sample were classified into two categories depending on their positive or negative environmental performance with respect to variables $E_{1}, E_{2}$, and $E_{3}$ :

- "Good performers" are companies that achieved negative values for the variables $E_{1}, E_{2}$, and $E_{3}$ in the period under analysis, demonstrating reduction in $\mathrm{CO}_{2}$ emissions and so a positive environmental performance.

- "Bad performers" are companies that achieved positive (or null) values for the variables $E_{1}, E_{2}$, and $E_{3}$ in the period under analysis, demonstrating increase in $\mathrm{CO}_{2}$ emissions and so a negative environmental performance.

Similarly, the 50 companies were divided into two groups according to their commitment to $\mathrm{CO}_{2}$ emissions reduction $\left(E_{4}\right)$ from $2008-2013$, specifically:

- "Good performers" are companies that achieved the reduction of $\mathrm{CO}_{2}$ emissions in at least three of the five two-year periods $\left(E_{4} \geq 0.6\right)$.

- "Bad performers" are companies that achieved the reduction of $\mathrm{CO}_{2}$ emissions in less than three two-year periods $\left(E_{4} \leq 0.4\right)$.

Four contingency tables, describing the relations between report completeness and each of the environmental performance variables $\left(E_{1}, E_{2}, E_{3}\right.$, and $\left.E_{4}\right)$, were prepared and tested. The only two tables showing a statistically significant relation with report completeness were those regarding "total percentage variation in $\mathrm{CO}_{2}$ emissions intensity" $\left(E_{1}\right)$ and "standardized slope of the regression line of $\mathrm{CO}_{2}$ emissions intensity" $\left(E_{3}\right)$ (Tables A1 and A2 in Appendix A). Figure 1a,b displays the distributions, 
in the contingency tables, of bad and good performing companies as percentage of their categories, for these two variables. For example, Figure 1a illustrates that $47 \%$ of good performers disclose a low number of quantitative environmental indicators in their sustainability reports.

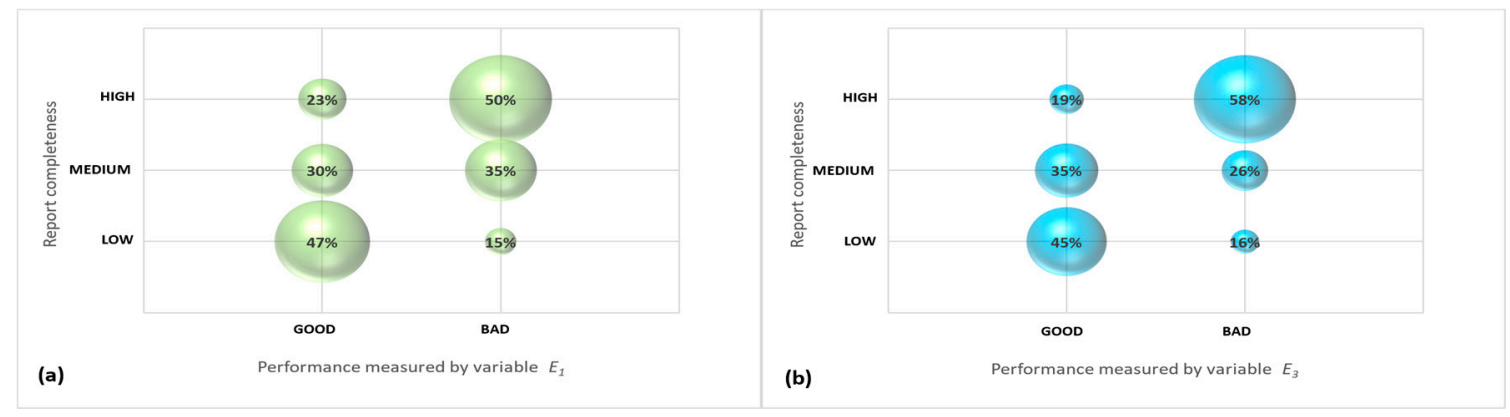

Figure 1. Distributions of good and bad performers (percentages) versus report completeness. Environmental performance measured by: (a) total percentage variation in $\mathrm{CO}_{2}$ emissions intensity $\left(E_{1}\right)$; and (b) standardized slope of the regression line of $\mathrm{CO}_{2}$ emissions intensity $\left(E_{3}\right)$.

These reveal that most companies achieving a good environmental performance (reductions in $\mathrm{CO}_{2}$ emissions, negative trend in $\mathrm{CO}_{2}$ emissions) published a low number of environmental indicators in their sustainability reports ( $47 \%$ in Figure 1a and $45 \%$ in Figure 1b), but that the opposite behavior was observed among the poor performers. Most of these published a high number of indicators $(50 \%$ in Figure $1 \mathrm{a}$ and $58 \%$ in Figure $1 \mathrm{~b}$ ).

A further analysis concerned the relation between a company's reporting experience, i.e., number of years of reporting, and the sustainability report's completeness. Using the binning approach described above, the range of values in the reporting experience was partitioned into three categories ("low", "medium", and "highly experienced"). The contingency table describing the relation between report completeness and reporting experience has statistical significance (Table A3, Appendix A). In particular, companies with more experience in sustainability reporting $(60 \%$ of "high" experienced companies in Figure 2) published a medium number of indicators; but few such companies (7\%) published reports that had a great degree of completeness. Companies with fewer years of reporting activity did not demonstrate any well-defined behaviour.

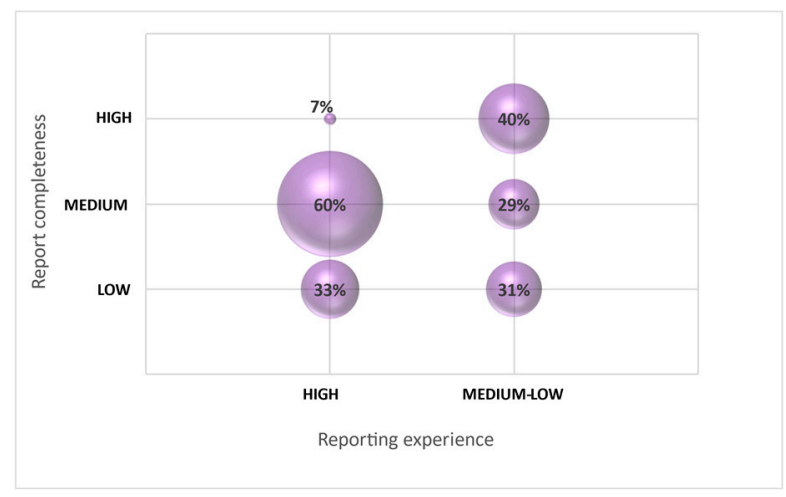

Figure 2. Distributions of high and low-medium experienced companies (percentages) versus report completeness (number of quantitative indicators reported).

Figure $3 \mathrm{a}, \mathrm{b}$ compares good and bad performers in terms of $E_{1}$, total percentage variation (in Figure 3a) and $E_{2}$, average annual percentage variation in $\mathrm{CO}_{2}$ emissions intensity (in Figure 3b). The two figures depict the difference in the percentages of bad and good performers that disclose each of the measurable environmental indicators found in the reports of the 50 companies. The two groups are not statistically different (Mann-Whitney U-test, $p>0.05$ ), but both Figure $3 \mathrm{a}, \mathrm{b}$ are of 
interest because they show that the companies with negative environmental performance are the ones that disclosed the largest number of indicators. Indeed, many indicators were published by a percentage of bad performers greater than the percentage of good ones. This result is evidence that the completeness of a sustainability report did not necessarily correspond to a real commitment to environmental sustainability. Actually, Figure $3 \mathrm{a}, \mathrm{b}$ presents a less than promising scenario since the worst performing companies are those who disclosed more details in their reports.

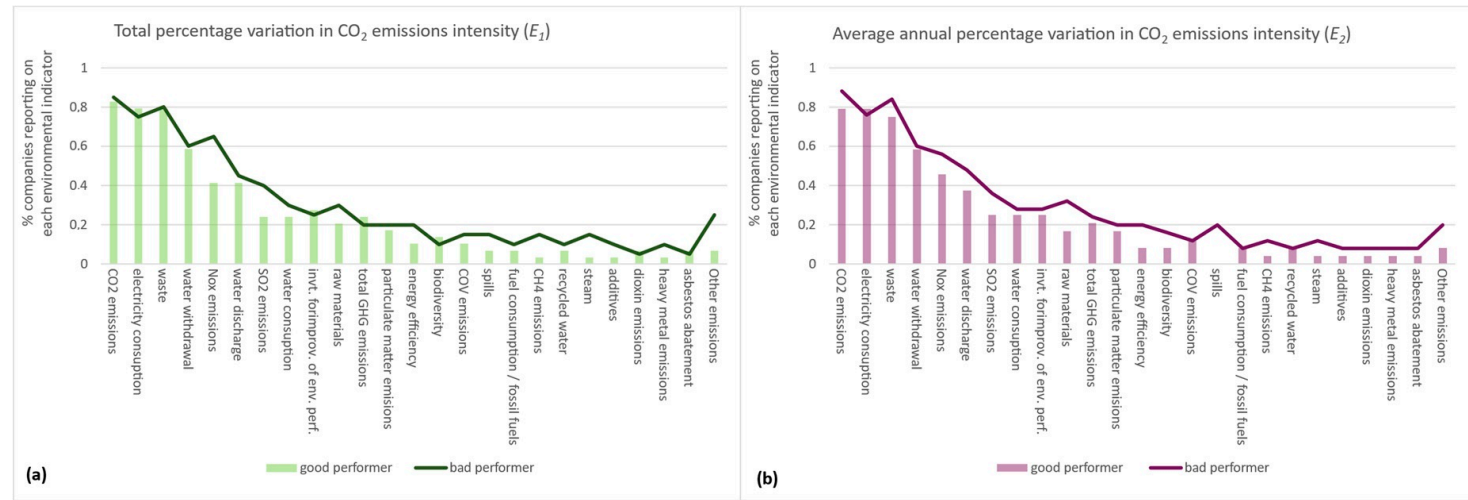

Figure 3. Percentages of good and bad performers reporting each of the quantitative performance indicators. Environmental performance measured by: (a) total percentage variation in $\mathrm{CO}_{2}$ emissions intensity $\left(E_{1}\right)$; and $(\mathbf{b})$ average annual percentage variation in $\mathrm{CO}_{2}$ emissions intensity $\left(E_{2}\right)$.

The most disclosed environmental indicator is clearly $\mathrm{CO}_{2}$ emissions. Moreover, this specific result validates the proposed methodological approach that advises the use of this quantitative indicator as a variable to measure environmental performance. This has previously been done by Sariannidis et al. [68], Brzobohatý and Janský [69], and Bernard et al. [8]. As noted, the validity of this choice for environmental performance assessment is also strengthened by the reliability of the source of the $\mathrm{CO}_{2}$ emission data, i.e., Union Registry for EU ETS.

Figure $4 \mathrm{a}, \mathrm{b}$ confirms the same behavior in the percentages of good and bad performers disclosing each environmental indicator in relation to the standardized slope of their regression line of $\mathrm{CO}_{2}$ emissions $\left(E_{3}\right)$, and their index of commitment to $\mathrm{CO}_{2}$ emissions reduction $\left(E_{4}\right)$, with the exception of water consumption in Figure $4 \mathrm{~b}$ and total GHG emissions in both Figure 4a,b (Mann-Whitney U-test, $p>0.05)$.
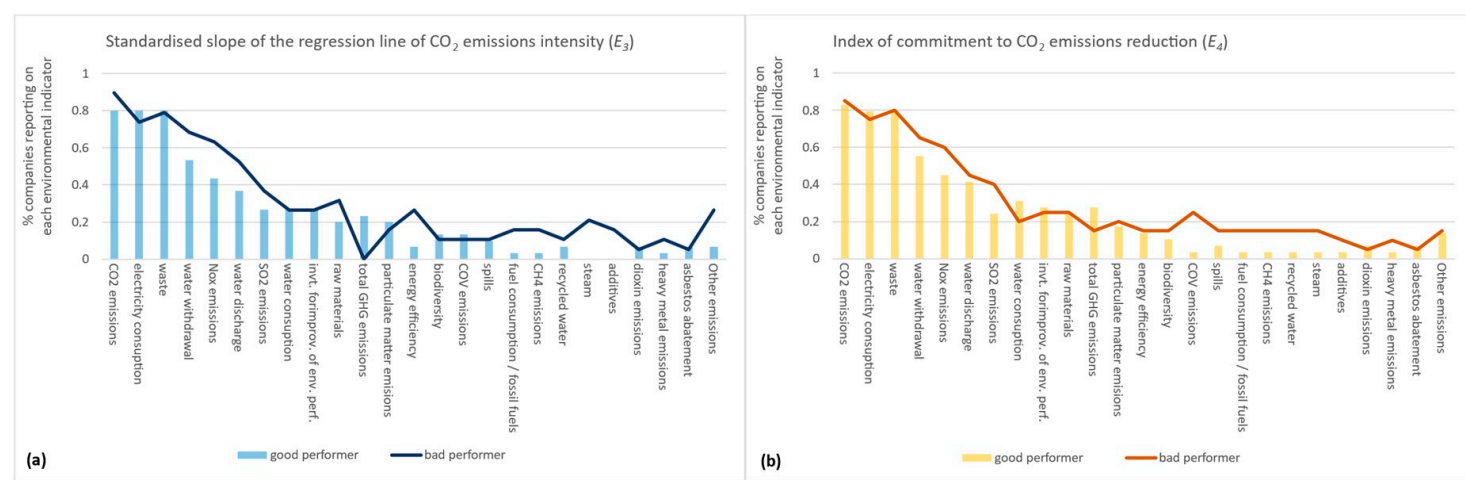

Figure 4. Percentages of good and bad performers reporting each of the quantitative performance indicators. Environmental performance measured by: (a) standardized slope of the regression line of $\mathrm{CO}_{2}$ emissions intensity $\left(E_{3}\right)$; and $(\mathbf{b})$ index of commitment to $\mathrm{CO}_{2}$ emissions reduction $\left(E_{4}\right)$.

\section{Discussion}

The purpose of this paper is to investigate the relationship between the completeness of quantitative data of sustainability reports and the companies' real commitment to environmental sustainability 
assessed by certified data on environmental performance. The results of the analyses raise concerns about the extent to which companies are truly accountable to their stakeholders. They reveal the potential credibility gap between the contents of the reports and the companies' true environmental sustainability performance, that could be a symptom of symbolic reporting or even greenwashing.

Literature has already raised doubts about the relationship between the real environmental performance of companies and the quality of their sustainability reports [15,43,49]. Michelon et al. [20] and Romero et al. [7] distinguish between substantial and symbolic approaches to sustainability reporting. Since the symbolic approach is aimed solely at improving the company image, it would almost certainly disclose misleading information and result in a credibility gap. Mahoney et al. [46] describe a greenwashing scenario in which the company intentionally publishes unsubstantiated or inconsequential green actions to obtain legitimacy with stakeholders, once again creating a credibility gap. Since various authors agree that completeness (e.g., $[10,20]$ ) and the presence of quantitative information (e.g., [7,51]) are both key indicators for the quality and reliability of the sustainability report, this paper used the completeness of quantitative information as a dimension in measuring the quality of the report.

Moreover, given that most companies already disclose information on $\mathrm{CO}_{2}$ emissions as a metric of sustainability and environmental performance $[8,21,67,68]$, the current study selected the Union Registry for EU ETS as a source of independent third-party information, intending to use the data on the companies' $\mathrm{CO}_{2}$ emissions in measuring their true commitment to environmental sustainability. Rather than simply using the volume of emissions, the choice of emissions intensity as a normalized indicator of environmental performance made it possible to assess the companies' behavior across different economic sectors, regardless of the size or age of the companies.

Furthermore, results show a weak, but significant correlation between report completeness and the environmental performance variables $E_{1}, E_{2}$, and $E_{3}$. The companies who publish a larger number of environmental quantitative indicators were more likely to be the ones with a weaker performance in reducing $\mathrm{CO}_{2}$ emissions. Analyses have also been conducted by means of contingency tables, and in terms of the percentages of good and bad performing companies that disclose each environmental indicator. The results show that companies with negative environmental performance (bad performers) are the ones that disclosed the largest number of quantitative environmental indicators. All of these analyses illustrate that a higher completeness of quantitative information does not necessarily indicate a greater commitment to environmental sustainability. These findings could suggest the potential existence of a credibility gap and possible signs of symbolic reporting. Because of the limitation of the sample size and time period analyzed, the results could be biased; but these results are comparable to those of Liu et al. [75] in the Chinese context. Those authors found that companies with lower environmental performance were likely to disclose more environmental information. More recently, Hummel and Schlick [76] examined the reporting activities of a sample of 388 European companies; and concluded that they are simply using sustainability reporting as a sophisticated way of obtaining legitimacy for their overall activities, without necessarily committing to related practices.

The findings of Meng et al. [51], examining a sample of 533 companies, could be interpreted as contradictory to this paper's results. According to these authors, both good and bad performers published a greater amount of "solid information" than medium-level ones, suggesting a nonlinear relationship between environmental performance and reporting practices. However, this paper's research differs from Meng et al.'s because of their prescreening process [51] and by their definition of a "good performer." These authors defined a good performer as one who is not focused on reduction in emissions intensity; but instead one who is interested in general compliance with environmental laws, in receiving environmental awards, and in demonstrating financial stability.

Overall, this paper's evidence contributes to what Michelon et al. [20] called the "increasing skepticism about the use of CSR reporting practices as tools used to enhance perceived accountability." It confirms the need to consider sustainability reports for what they are: a corporate publication, not a technical report of environmental performance or the expression of a level of sustainability commitment. 
In fact, Cohen [77] and Liu et al. [75] previously argued that sustainability reporting practices do not reflect actual environmental performance; and Bernard et al. [8] describe the sustainability report as the "amount of information a company is willing to disclose."

In the final analysis, the company's reporting experience was not significantly correlated with either the company's environmental performance or the completeness of its reports. The contingency table analysis shows that companies with more experience in reporting published a medium number of indicators, while those with less experience do not have a well-defined behaviour.

This paper's results are not aligned with those of some authors who found a higher sustainability performance in companies that practice GRI standard reporting [20,78]. In the above sample, $80 \%$ of companies followed the GRI standard; but $58 \%$ of these same companies did not have a consistent positive environmental performance $\left(E_{1}<0 ; E_{2}<0 ; E_{3} \leq-0.25\right.$ and $\left.E_{4} \geq 0.6\right)$. This supports the deduction of Tang and Demeritt [21] that companies publish their environmental performance in terms of $\mathrm{CO}_{2}$ emissions in response to financial incentives, social pressure, or regulatory obligations. Furthermore, these same authors find that there is not enough supporting evidence to conclude that the companies' carbon emissions reporting processes are fueling any real reductions.

\section{Conclusions}

The credibility of sustainability reports can affect sustainable development and especially the relationship between stakeholders and companies. Among stakeholders, the reliability of sustainability reports is particularly important to financial analysts and investors who need to assess the competitive opportunities and threats to the businesses that increasingly involve environmental and social issues. Not having ready access to other information on sustainability, investors are forced to rely upon what is contained in sustainability reports.

This study improves the understanding of companies' accountability towards stakeholders by developing a methodological approach for the analysis of their reports. Furthermore, it highlights the importance of third-party certified data for detection of credibility gaps in the sustainability reports. To perform this analysis, the number of quantitative environmental indicators was taken as a dimension of the quality of the companies' sustainability reports. Their real conduct regarding environmental sustainability was measured based on the reduction of the $\mathrm{CO}_{2}$ emissions intensity certified by Union Registry for EU ETS data. $\mathrm{CO}_{2}$ emissions intensity represented an adequate proxy for this purpose as it delineates the outcomes of better environmental performance within organizations, i.e., implementation of green energy supply, improvements in production or service efficiency, among others. Results indicate that the completeness of quantitative information in the companies' sustainability reports does not necessarily relate to better environmental performance and greater commitment towards environmental sustainability. It reinforces previous doubts concerning the companies' true accountability on sustainability issues toward their stakeholders.

This study has limitations because the sample size came from a single country. The novelty of this study is to rely solely on data certified by third parties, restricting the possibility of increasing the number of indicators. Consequently, another limitation has been the analysis of a single environmental indicator, $\mathrm{CO}_{2}$ emissions, as a proxy for the company's real commitment to environmental sustainability.

Future research could focus on a larger multinational sample in an extended time period. Moreover, other certified third-party environmental indicators could be added to the analysis with third-party certified data on materials recycling, water, or energy consumption, among others. Furthermore, extending the research to other dimensions of sustainability outside the environment would be interesting.

Author Contributions: The authors contributed equally to this work. All authors have read and agreed to the published version of the manuscript.

Funding: This research received no external funding.

Conflicts of Interest: The authors declare no conflict of interest. 


\section{Appendix A}

Table A1. Contingency table: report completeness (rows) and performance measured by $E_{1}$ (columns).

\begin{tabular}{ccccc}
\hline \multicolumn{5}{c}{ Performance Measured by $\boldsymbol{E}_{\mathbf{1}}$} \\
\hline & & Bad & Good & Total \\
\hline \multirow{3}{*}{ Report completeness } & High & 10 & 7 & 17 \\
& Medium & 7 & 9 & 16 \\
& Low & 3 & 14 & 17 \\
\hline & Total & 20 & 30 & 50 \\
\hline & $\chi^{2}=6.143 ; \mathrm{df}=2 ; p$-value $=0.046$.
\end{tabular}

Table A2. Report completeness (rows) and performance measured by $E_{3}$ (columns).

\begin{tabular}{|c|c|c|c|c|}
\hline \multicolumn{5}{|c|}{ Performance Measured by $E_{3}$} \\
\hline & & Bad & Good & Total \\
\hline \multirow{4}{*}{ Report completeness } & High & 11 & 6 & 17 \\
\hline & Medium & 5 & 11 & 16 \\
\hline & Low & 3 & 14 & 17 \\
\hline & Total & 19 & 31 & 50 \\
\hline
\end{tabular}

Table A3. Contingency table: report completeness (rows) and reporting experience (columns).

\begin{tabular}{|c|c|c|c|c|}
\hline \multicolumn{5}{|c|}{ Reporting Experience } \\
\hline & & High & Medium-Low & Total \\
\hline \multirow{4}{*}{ Report completeness } & High & 1 & 14 & 15 \\
\hline & Medium & 9 & 10 & 19 \\
\hline & Low & 5 & 11 & 16 \\
\hline & Total & 15 & 35 & 50 \\
\hline
\end{tabular}

\section{References}

1. Falkenberg, J.; Brunsæl, P. Corporate social responsibility: A strategic advantage or a strategic necessity? J. Bus. Ethics 2011, 99, 9-16. [CrossRef]

2. Gerstlberger, W.; Præst, M.; Knudsen; Stampe, I. Sustainable development strategies for product innovation and energy efficiency. Bus. Strategy Environ. 2014, 23, 131-144. [CrossRef]

3. Walsh, P.R.; Dodds, R. Measuring the Choice of Environmental Sustainability Strategies in Creating a Competitive Advantage. Bus. Strategy Environ. 2017, 26, 672-687. [CrossRef]

4. Burritt, R.L.; Schaltegger, S. Sustainability accounting and reporting: Fad or trend? Account. Audit. Account. J. 2010, 23, 829-846. [CrossRef]

5. Dhaliwal, D.S.; Radhakrishnan, S.; Tsang, A.; Yang, Y.G. Nonfinancial disclosure and analyst forecast accuracy: International evidence on corporate social responsibility disclosure. Account. Rev. 2012, 87, 723-759. [CrossRef]

6. Zhao, C.; Song, H.; Chen, W. Can social responsibility reduce operational risk: Empirical analysis of Chinese listed companies. Technol. Forecast. Soc. Chang. 2016, 112, 145-154. [CrossRef]

7. Romero, S.; Ruiz, S.; Feijoo, B.F. Sustainability reporting and stakeholder engagement in Spain: Different instruments, different quality. Bus. Strategy Environ. 2019, 28, 221-232. [CrossRef]

8. Bernard, S.; Abdelgadir, S.; Belkhir, F. Does GRI reporting impact environmental sustainability? An industryspecific analysis of $\mathrm{CO}_{2}$ emissions performance between reporting and non-reporting companies. J. Sustain. Dev. 2015, 8, 190-205. [CrossRef] 
9. Birkey, R.N.; Michelon, G.; Patten, D.M.; Sankara, J. Does assurance on CSR reporting enhance environmental reputation? An examination in the US context. Account. Forum 2016, 40, 143-152. [CrossRef]

10. Bouten, L.; Everaert, P.; van Liedekerke, L.; de Moor, L.; Christiaens, J. Corporate social responsibility reporting: A comprehensive picture? Account. Forum 2011, 35, 187-204. [CrossRef]

11. Bouten, L.; Everaert, P.; Roberts, R.W. How a two-step approach discloses different determinants of voluntary social and environmental reporting. J. Bus. Financ. Account. 2012, 39, 567-605. [CrossRef]

12. Cho, C.H.; Michelon, G.; Patten, D.M. Impression management in sustainability reports: An empirical investigation of the use of graphs. Account. Public Interest 2012, 12, 16-37. [CrossRef]

13. Higgins, C.; Tang, S.; Stubbs, W. On managing hypocrisy: The transparency of sustainability reports. J. Bus Res. 2020, 114, 395-407. [CrossRef]

14. Husillos, J.; Larrinaga, C.; Alvarez, M.J. The emergence of triple bottom line reporting in Spain. Rev. Esp. Financ. Contab. 2011, 60, 195-219. [CrossRef]

15. Gray, R. Is accounting for sustainability actually accounting for sustainability and how would we know? An exploration of narratives of organisations and the planet. Account. Organ. Soc. 2010, 35, 47-62. [CrossRef]

16. Montiel, I.; Ceballos, J.D. Defining and measuring corporate sustainability: Are we there yet? Organ. Environ. 2014, 27, 113-139. [CrossRef]

17. Helfaya, A.; Whittington, M.; Alawattage, C. Exploring the quality of corporate environmental reporting: Surveying preparers' and users' perceptions. Account. Audit. Account. J. 2018, 32, 163-193. [CrossRef]

18. Ching, H.Y.; Gerab, F. Sustainability reports in Brazil through the lens of signaling, legitimacy and stakeholder theories. Soc. Responsib. J. 2017, 13, 95-110. [CrossRef]

19. Helfaya, A.; Whittington, M. Does designing environmental sustainability disclosure quality measures make a difference? Bus. Strategy Environ. 2019, 28, 525-541. [CrossRef]

20. Michelon, G.; Pilonato, S.; Ricceri, F. CSR reporting practices and the quality of disclosure: An empirical analysis. Crit. Perspect. Account. 2015, 33, 59-78. [CrossRef]

21. Tang, S.; Demeritt, D. Climate change and mandatory carbon reporting: Impacts on business process and performance. Bus. Strategy Environ. 2018, 27, 437-455. [CrossRef]

22. Suchman, M.C. Managing legitimacy: Strategic and institutional approaches. Acad. Manag. Rev. 1995, 20, 571-610. [CrossRef]

23. O'Donovan, G. Environmental disclosures in the annual report: Extending the applicability and predictive power of legitimacy theory. Account. Audit. Account. J. 2002, 15, 344-371. [CrossRef]

24. Nikolaeva, R.; Bicho, M. The role of institutional and reputational factors in the voluntary adoption of corporate social responsibility reporting standards. J. Acad. Mark. Sci. 2011, 39, 136-157. [CrossRef]

25. Marquis, C.; Qian, C. Corporate social responsibility reporting in China: Symbol or substance? Organ. Sci. 2014, 25, 127-148. [CrossRef]

26. Wei, Z.; Shen, H.; Zhou, K.Z.; Li, J.J. How does environmental corporate social responsibility matter in a dysfunctional institutional environment? Evidence from China. J. Bus. Ethics 2017, 140, 209-223. [CrossRef]

27. Hahn, R.; Kühnen, M. Determinants of sustainability reporting: A review of results, trends, theory, and opportunities in an expanding field of research. J. Clean. Prod. 2013, 59, 5-21. [CrossRef]

28. Kolk, A. The social responsibility of international business: From ethics and the environment to CSR and sustainable development. J. World Bus. 2016, 51, 23-34. [CrossRef]

29. Schneider, A. Reflexivity in sustainability accounting and management: Transcending the economic focus of corporate sustainability. J. Bus. Ethics 2015, 127, 525-536. [CrossRef]

30. Skouloudis, A.; Evangelinos, K.; Kourmousis, F. Assessing non-financial reports according to the global reporting initiative guidelines: Evidence from Greece. J. Clean. Prod. 2009, 18, 426-438. [CrossRef]

31. Lopes, P.; Rodrigues, L. Accounting for financial instruments: An analysis of the determinants of disclosure in the Portuguese stock exchange. Int. J. Account. 2007, 42, 25-56. [CrossRef]

32. Laufer, W. Social accountability and corporate greenwashing. J. Bus. Ethics 2003, 43, 253-261. [CrossRef]

33. Milne, M.J.; Patten, D.M. Securing organizational legitimacy: An experimental decision case examining the impact of environmental disclosures. Account. Audit. Account. J. 2002, 5, 372-405. [CrossRef]

34. Badia, F.; Bracci, E.; Tallaki, M. Quality and diffusion of social and sustainability reporting in Italian public utility companies. Sustainability 2020, 12, 4525. [CrossRef]

35. Lock, I.; Seele, P. The credibility of CSR (corporate social responsibility) reports in Europe. Evidence from a quantitative content analysis in 11 countries. J. Clean. Prod. 2016, 122, 186-200. 
36. Mazzotta, R.; Bronzetti, G.; Veltri, S. Are mandatory non-financial disclosures credible? Evidence from Italian listed companies. Corp. Soc. Responsib. Environ. Manag. 2020, 27, 1900-1913. [CrossRef]

37. Hsueh, J.W.J. Governance structure and the credibility gap: Experimental evidence on family businesses' sustainability reporting. J. Bus. Ethics 2018, 153, 547-568.

38. Davies, D.M.M.; Brennan, N. Discretionary disclosure strategies in corporate narratives: Incremental information or impression management? J. Account. Lit. 2007, 26, 116-196.

39. Davies, D.M.M.; Brennan, N. A conceptual framework of impression management: New insights from psychology, sociology and critical perspectives. Account. Bus. Res. 2011, 41, 415-437. [CrossRef]

40. Diouf, D.; Boiral, O. The quality of sustainability reports and impression management: A stakeholder perspective. Account. Audit. Account. J. 2017, 30, 643-667.

41. Courtis, J.K. Corporate report obfuscation: Artefact or phenomenon? Br. Account. 2004, 36, 291-312. [CrossRef]

42. Dienes, D.; Sassen, R.; Fischer, J. What are the drivers of sustainability reporting? A systematic review. Sustain. Account. Manag. Policy J. 2016, 7, 154-189. [CrossRef]

43. Adams, C.; Evans, R. Accountability, completeness, credibility and the audit expectations gap. J. Corp. Citizsh. 2004, 14, 97-115. [CrossRef]

44. Beck, A.C.; Campbell, D.; Shrives, P.J. Content analysis in environmental reporting research: Enrichment and rehearsal of the method in a British-German context. Br. Account. Rev. 2010, 42, 207-222. [CrossRef]

45. Guthrie, J.; Cuganesan, S.; Ward, L. Industry specific social and environmental reporting: The Australian food and beverage industry. Account. Forum 2008, 32, 1-15. [CrossRef]

46. Mahoney, L.; Thorne, L.; Cecil, L.; LaGore, W. A research note on standalone corporate social responsibility reports: Signaling or greenwashing? Crit. Perspect. Account. 2013, 24, 350-359. [CrossRef]

47. Belkhir, L.; Bernard, S.; Abdelgadir, S. Does GRI reporting impact environmental sustainability? A crossindustry analysis of $\mathrm{CO}_{2}$ emissions performance between GRI-reporting and non-reporting companies. Manag. Environ. Qual. Int. J. 2017, 28, 138-155. [CrossRef]

48. Siano, A.; Vollero, A.; Conte, F.; Amabile, S. "More than words": Expanding the taxonomy of greenwashing after the Volkswagen scandal. J. Bus. Res. 2017, 71, 27-37. [CrossRef]

49. LeBlanc, D. Towards integration at last? The sustainable development goals as a network of targets. Sustain. Dev. 2015, 23, 176-187. [CrossRef]

50. Schönherr, N.; Findler, F.; Martinuzzi, A. Exploring the interface of CSR and the sustainable development goals. Transnatl. Corp. 2017, 24, 33-47. [CrossRef]

51. Meng, X.H.; Zeng, S.X.; Shi, J.J.; Qi, G.Y.; Zhang, Z. The relationship between corporate environmental performance and environmental disclosure: An empirical study in China. J. Environ. Manag. 2014, 145, 357-367. [CrossRef] [PubMed]

52. Font, X.; Walmsley, A.; Cogotti, S.; McCombes, L.; Häusler, N. Corporate social responsibility: The disclosure of performance gap. Tour. Manag. 2012, 33, 1544-1553. [CrossRef]

53. Testa, F.; Miroshnychenko, I.; Barontini, R.; Frey, M. Does it pay to be a greenwasher or a brownwasher? Bus. Strategy Environ. 2018, 27, 1104-1116. [CrossRef]

54. Brundtland, G. Our Common Future: Report of the World Commission on Environment and Development. 1987. Available online: http://www.un-documents.net/our-common-future.pdf (accessed on 18 December 2020).

55. Dias, V.; Villazon Montalvan, R.A. Perspectivas sustentáveis da implantação de um forno alternativo de carvoejamento no município de Biguaçu/SC e suas implicações legais. Rev. Int. Direito Ambient. 2013, 2, 317-332.

56. Elkington, J. Cannibals with Forks: The Triple Bottom Line of 21st Century Business; Capstone: Oxford, UK, 1997.

57. United Nations. Transforming Our World: The 2030 Agenda for Sustainable Development A/RES/70/1; de Resolution Adopted by the General Assembly on 25 September 2015. Available online: https://www.un. org/en/development/desa/population/migration/generalassembly/docs/globalcompact/A_RES_70_1_E.pdf (accessed on 18 December 2020).

58. Sánchez, L. Avaliação de Impacto Ambiental: Conceitos e Métodos; Oficina de Textos: São Paulo, Brazil, 2013.

59. Sánchez, L.; Hacking, T. An approach to linking environmental impact assessment and environmental management systems. Impact Assess. Proj. Apprais. 2002, 20, 25-38. [CrossRef]

60. Kemerich, P.D.; Ritter, L.G.; Borba, W.F. Indicadores de sustentabilidade ambiental: Métodos e aplicações. Rev. Monogr. Ambient. REMOA 2014, 13, 3723-3736. [CrossRef] 
61. Rahdari, A.; Rostamy, A. Designing a General Set of Sustainability Indicators at the Corporate Level. J. Clean Prod. 2015, 108, 757-771. [CrossRef]

62. Marzall, K.; Almeida, J. Indicadores De Sustentabilidade Para Agroecossistemas: Estado da arte, limites e potencialidades de uma nova ferramenta para avaliar o desenvolvimento sustentável. Cad. Ciênc. Tecnol. 2000, 7, 41-59.

63. UNFCC (United Nations Framework Convention on Climate Change). Kyoto Protocol to the United Nations Framework Convention on Climate Change. In Proceedings of the COP3, Kyoto, Japan, 11 December 1997. Available online: https://www.eea.europa.eu/policy-documents/kyoto-protocol-to-the-un (accessed on 18 December 2020).

64. Council of the EU. Directive 2003/87/EC of the European Parliament and of the Council of 13 October 2003 Establishing a Scheme for Greenhouse Gas Emission Allowance Trading within the Community and Amending Council Directive 96/61/EC; 25 October 2003. Available online: https://eur-lex.europa.eu/LexUriServ/LexUriServ.do?uri=OJ:L: 2003:275:0032:0046:en:PDF (accessed on 18 December 2020).

65. di Pillo, F.; Gastaldi, M.; Levialdi, N.; Miliacca, M. Environmental Performance Versus Economic-financial Performance: Evidence from Italian Firms. Int. J. Energy Econ. Policy 2017, 7, 98-108.

66. Fezzigna, P.; Borghesi, S.; Caro, D. Revising emission responsibilities through consumption-based accounting: A European and post-Brexit perspective. Sustainability 2019, 11, 488. [CrossRef]

67. Ren, S.; Hu, Y.; Zheng, J.; Wang, Y. Emissions trading and firm innovation: Evidence from a natural experiment in China. Technol. Forecast. Soc. Chang. 2020, 155, 119989. [CrossRef]

68. Sariannidis, N.; Zafeiriou, E.; Giannarakis, G.; Arabatzis, G. $\mathrm{CO}_{2}$ emissions and financial performance of socially responsible firms: An empirical survey. Bus. Strategy Environ. 2013, 22, 109-120. [CrossRef]

69. Brzobohatý, T.; Janský, P. Impact of $\mathrm{CO}_{2}$ Emissions Reductions on Firms' Finance in an Emerging Economy: The Case of the Czech Republic. Transit. Stud. Rev. 2010, 17, 725-736. [CrossRef]

70. Wiedmann, T.; Barrett, J. A greenhouse gas footprint analysis of UK Central Government, 1990-2008. Environ. Sci. Policy 2011, 14, 1041-1051. [CrossRef]

71. Global Carbon Project. Supplemental Data of Global Carbon Budget 2019 (Version 1.0). Global Carbon Project, ICOS. 2019. Available online: https://doi.org/10.18160/gcp-2019 (accessed on 18 December 2020).

72. Albertini, E. A descriptive analysis of environmental disclosure: A longitudinal study of French companies. J. Bus. Ethics 2014, 121, 233-254. [CrossRef]

73. Capece, G.; di Pillo, F.; Gastaldi, M.; Levialdi, N.; Miliaca, M. Examining the effect of managing GHG emissions on business performance. Bus. Strategy Environ. 2017, 26, 1041-1060. [CrossRef]

74. Scott, P.; Williams, R.; Ho, K. Forming Categories in Exploratory Data Analysis and Data Mining. In International Symposium on Intelligent Data Analysis; Springer: Berlin/Heidelberg, Germany, 1997; pp. 235-246. [CrossRef]

75. Liu, Z.; Liu, T.; McConkey, B.; Li, X. Empirical analysis on environmental disclosure and environmental performance level of listed steel companies. Energy Procedia 2011, 5, 2211-2218. [CrossRef]

76. Hummel, K.; Schlick, C. The relationship between sustainability performance and sustainability disclosure-Reconciling voluntary disclosure theory and legitimacy theory. J. Account. Public Policy 2016, 35, 455-476. [CrossRef]

77. Cohen, E. The A+ Myth of Sustainability Reporting: Stop the Hype. 2012. Available online: http://csr-reporting. blogspot.com/2012/06/a-myth-of-sustainability-reporting-stop.html (accessed on 18 December 2020).

78. Fortanier, F.; Kolk, A.; Pinkse, J. Harmonization in CSR reporting. Manag. Int. Rev. 2011, 51, 665-696. [CrossRef]

Publisher's Note: MDPI stays neutral with regard to jurisdictional claims in published maps and institutional affiliations.

(C) 2020 by the authors. Licensee MDPI, Basel, Switzerland. This article is an open access article distributed under the terms and conditions of the Creative Commons Attribution (CC BY) license (http://creativecommons.org/licenses/by/4.0/). 